\title{
The frog prince-ss: A molecular formula for dorsoventral patterning in Xenopus
}

\author{
Hazel L. Sive \\ Whitehead Institute for Biomedical Research, Cambridge, Massachusetts 02142 USA
}

Determination of the dorsoventral (D/V) axis in the frog, Xenopus laevis, begins soon after fertilization, and D/V asymmetry is present in all germ layers from early cleavage onward. Determinants of dorsal axial position may include members of the Wnt gene family and a novel gene, noggin, acting in conjunction with an activin-like protein. Formation of mesodermal tissues is a multistep process. Activins appear to be required during early cleavage stages for initial induction of both dorsal and ventral mesoderm, whereas fibroblast growth factors (FGFs) appear to be required later in embryogenesis and induce posterior (dorsal and ventral) mesoderm. Subsequent to initial induction, the fates of mesodermal tissues are modified by both active dorsalizing and ventralizing forces that operate during late blastula and gastrula stages. Dorsalizing factors may include Wnt proteins, Noggin, activins, and members of the FGF family, whereas ventralizing factors may include the Xwnt- 8 protein as well as bone morphogenetic protein-4 (BMP-4 or DVR-4).

\section{$\mathrm{D} / \mathrm{V}$ patterning in Xenopus}

Garbed in deceptively subtle colors, the frog, Xenopus laevis, continues to play a commanding role in solving the riddle of vertebrate embryogenesis. The riddle can be stated quite simply. How does an embryo generate positional information, and what is the molecular basis for the information? Of course, the simple question is almost meaningless, because we know enough from invertebrate systems to understand that development is complex. Many steps are required to turn the egg into an embryo; and like fractals, the complexity does not diminish as one looks more closely. In this review I therefore focus on just some of the early steps in Xenopus axial patterning, specifically formation of the $\mathrm{D} / \mathrm{V}$ axis.

Its genetic intractability notwithstanding, Xenopus is an attractive animal for developmental studies because its embryos are large and easy to dissect into pieces that can be assayed for their inductive potential or for the responses of which they are capable. These powerful analyses of cell interactions have largely shaped current thought about inductive mechanisms that may operate in other organisms less accessible to experimental manipulation. Where tested, predictions from Xenopus have held true, strengthening the notion that what one learns in frogs is of very general importance.

Formation of the D/V axis initiates Xenopus axial patterning, with most anteroposterior axis formation occurring later but intimately and obscurely, dependent on the $\mathrm{D} / \mathrm{V}$ pattern. Anteroposterior patterning has been admirably reviewed recently (Slack and Tannahill 1992). In describing the mechanisms of $\mathrm{D} / \mathrm{V}$ patterning, I travel through the embryo, from vegetal to animal pole, beginning before fertilization and ending at early gastrula stages, describing the phenomena and molecular correlates that may be involved.

\section{Asymmetry in the unfertilized egg}

Axial patterning builds upon the asymmetry in the unfertilized egg that extends from animal to vegetal pole. Contained and sometimes localized within the egg is a bewildering array of potential regulatory molecules. Because a great deal of axial patterning occurs before zygotic transcription begins at the mid-blastula transition [(MBT) when the embryo contains $\sim 4000$ cells] (Kirschner et al. 1985), this array serves as a store of proteins or RNAs that can be activated at appropriate times. Several RNAs are specifically localized to the rigid cortex in the vegetal hemisphere and may play a role in early patterning. The most famous, which lent precedence to the localization of "determinants" in vertebrate embryos is $\mathrm{Vg}-1$, a gene still in search of a function, despite its similarity to the transforming growth factor- $\beta$ (TGF- $\beta$ ) family (Weeks and Melton 1987). Also localized to the vegetal cortex is a newly isolated gene, XCAT-2, which displays intriguing similarity to part of the Drosophila posterior determinant Nanos (Mosquera et al. 1993). Numerous mesoderm-inducing factors, including Noggin (Smith and Harland 1992), activins (Asashima et al. 1991), members of the FGF family (Kimelman and Kirschner 1987; Slack and Isaacs 1989|, and their receptors (Musci et al. 1990; Hemmati-Brivanlou et al. 1992; Matthews et al. 1992) are also stored in the egg.

\section{Rotation and the $D / V$ axis}

Soon after fertilization, opposite sides of the embryo become specified as dorsal and ventral. The position of the dorsal midline lies $\sim 180^{\circ}$ from the site of sperm entry and may also be influenced by gravitational effects dur- 
ing oocyte maturation (M. Danilchik, pers. comm.). Absolutely correlated with $\mathrm{D} / \mathrm{V}$ specification is a relative rotation of the rigid surface cortex and the underlying cytoplasm that occurs within the first cell cycle after fertilization (Gerhart et al. 1989; Fig. 1). When rotation is prevented (e.g., by irradiation with UV light during the first cell cycle), the embryo develops no dorsal axis and has been assumed to represent a ventralized state. With two (or more) sequential rotations, applied manually, two (or more) dorsal axes develop, indicating that the rotation uncovers a nonlimiting amount of dorsal information in the embryo. Identifying the primary target of rotation remains a major challenge, but several pieces of data suggest that it resides in the vegetal hemisphere. One set of corroborative data is the localization of RNAs encoding putative regulatory proteins to the vegetal cortex (Weeks and Melton 1987; Pondel and King 1988; Mosquera et al. 1993). Consistent with this is the demonstration that the developing oocyte contains two targets of UV light. One is the corticocytoplasmic rotation, which can be compensated for by manual rotation; the other target cannot be compensated for by rotation and may be an RNA or protein with properties of a dorsal determinant (Elinson and Pasceri 1989). Once the oocyte has matured into an egg, the rotation-insensitive target disappears, suggesting that latent dorsal information has been established by this stage. By the four-cell stage, $\mathrm{D} / \mathrm{V}$ information (determinants) is clearly asymmetrically distributed, because removal of a presumptive dorsal blastomere leads to extreme dorsal deficiency of the resulting embryo, and removal of ventral blastomeres leads to hyperdorsalized embryos (Cooke 1985). Two classes of molecule, Wnt proteins and Noggin (see below), have recently emerged as candidates for a dorsal determinant.

\section{Formation of the vegetal-inducing centers}

Two functionally distinct inducing centers are set up in the vegetal endoderm soon after fertilization and induce adjacent cells in the equatorial region (or marginal zone) to form dorsal and ventral mesoderm. This has been revealed by two assays. The first, devised by Nieuwkoop, showed that isolated animal hemisphere cells (animal caps, Fig. 1) that are destined to form ectodermal tissues (including epidermis and neural derivatives) could instead be induced to mesodermal fates when recombined in vitro with vegetal cells (largely endodermal tissue, presumptive gut, and nutritive yolk) (Nieuwkoop 1973). Dorsal vegetal cells are able to induce dorsal mesoderm, including notochord and muscle, and have been termed the Nieuwkoop Center (N.C.) (Gerhart et al. 1989), whereas ventral vegetal cells are capable of inducing more ventral mesodermal cell types, including blood and mesenchyme (see Smith 1989). This animal cap assay has been used extensively to assay for mesoderm inducers; although, because the animal cap is destined to form ectodermal and not mesodermal tissues, the assay primarily monitors respecification of presumptive ectoderm to mesoderm. True mesodermal precursors are difficult to isolate because their determination has begun by the 32-cell stage, the first time that a separate layer of marginal zone cells has formed (Fig. 1). Activity of vegetal-inducing centers has been demonstrated by a second type of assay. Dorsal axial structures can be restored to a UV-treated blastula, or a secondary axis can be induced on the ventral side of a normal embryo, by introduction of dorsal (N.C.), but not ventral, vegetal blastomeres from 32-cell stage embryos (Gimlich and Gerhart 1984; Kageura 1990). By this assay, the N.C. loses the ability to restore a complete $\mathrm{D} / \mathrm{V}$ axis before the onset of zygotic transcription.

\section{Wnt and noggin genes may specify the N.C.}

Recent assays for genes that can generate a N.C. have attempted to restore dorsal axial structures to UVtreated embryos by microinjection of specific tran-

Figure 1. Hypothetical scheme of steps leading to D/V patterning. Surface views of embryos from fertilization until early gastrula are shown. Within the first cell cycle after fertilization, the surface cortex and underlying cytoplasm undergo a relative rotation that is required for normal dorsal axis formation. The direction of cortical rotation is shown. The dorsal side of the embryo lies approximately opposite the sperm entry point. By the four-cell stage, localized determinants activated by the corticocytoplasmic rotation define the $\mathrm{D} / \mathrm{V}$ axis. Dorsal determinants are likely to include the products of Wnt and noggin genes. Dorsal vegetal-inducing (N.C.) and ventral vegetal-inducing centers signal marginal zone (equatorial) cells to form dorsal (notochord) and ventral (blood and mesenchyme) mesoderm directly (arrows). Although it is not clear when the vegetal-inducing centers become active, they are fully active by the 32-cell stage, when latitudinal cleavages separate the vegetal endoderm from the equatorial marginal zone. The initial inducing signals likely include activin, both ventrally and dorsally - the latter in conjunction with a Wnt gene or noggin, which potentiates the action of activin. Marginal zone induction has clearly begun by the 32-cell stage, although dorsal mesoderm (organizer) is not fully induced until mid- to late-blastula stages. The effects of Wnt genes and noggin extend into the animal hemisphere and enhance the response of dorsal animal cap cells to the mesoderm inducers, activin and FGF. In the late blastula, induced dorsal (organizer) and ventral mesoderm send out signals within the marginal zone to refine the mesodermal pattern into additional dorsolateral (presumptive muscle) and ventrolateral (presumptive lateral plate) domains. The dorsalizing signals may include a Wnt protein and/or Noggin in conjunction with activin or FGF, ventralizing signals may include Xwnt-8, BMP-4, possibly FGF, and possibly retinoids. At late blastula, the organizer sends out an additional vertical signal, with unknown identity, which enhances the response of dorsal animal cap cells to neural induction. By early gastrula, the basic coordinates of the $\mathrm{D} / \mathrm{V}$ pattern are in place, although many more steps are required to refine this pattern into the familiar shape of a hatching-stage animal and to effect terminal differentiation. The fate map of the early gastrula is plotted onto a hatching-stage animal (Keller 1976; Dale and Slack 1987a). The ectoderm gives rise to the nervous system, including the eye, and to non-neural organs such as the anterior cement gland; the ventral ectoderm forms the epidermis of the skin that covers the entire animal. 


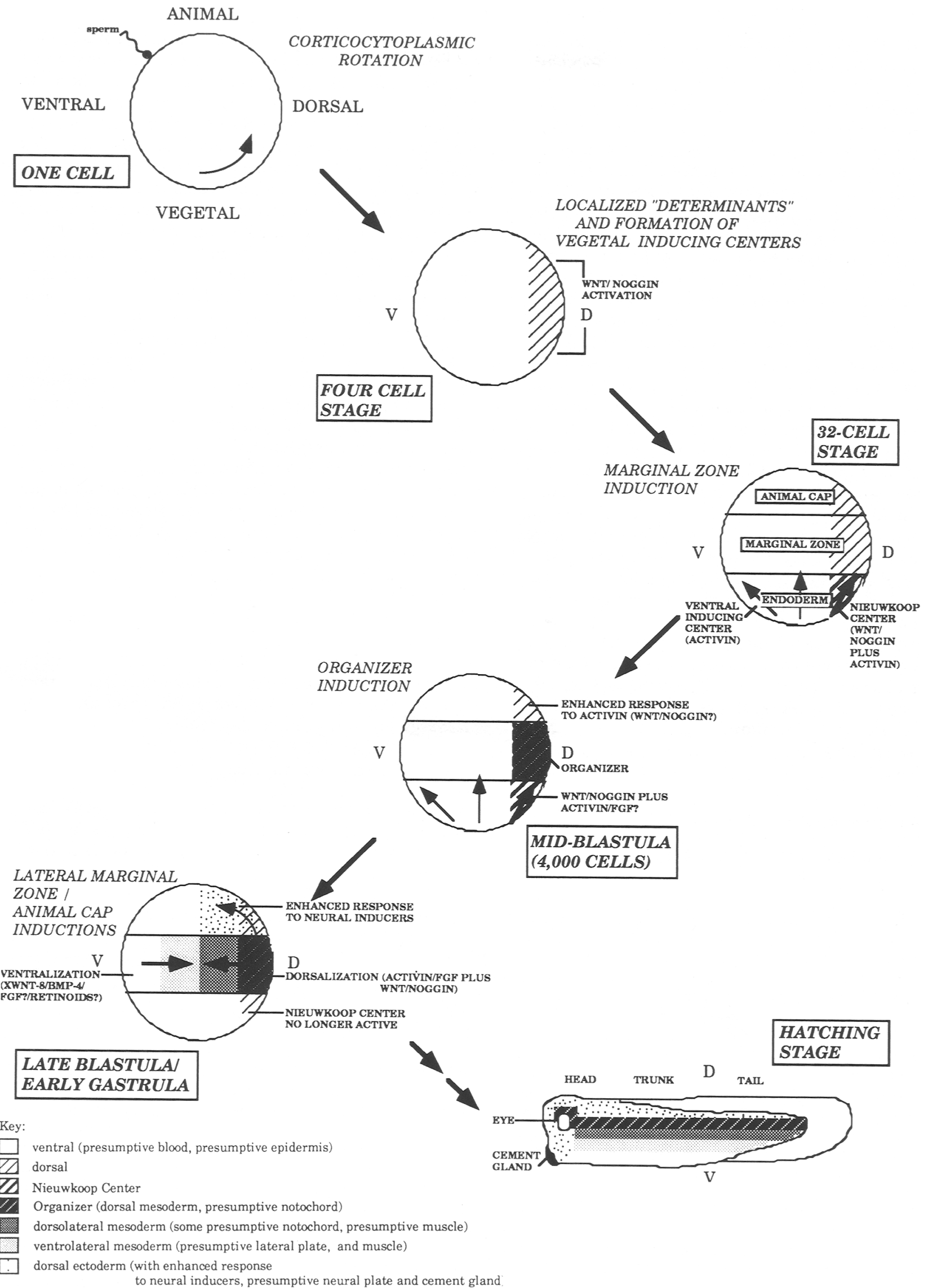


scripts. Two genes, Xwnt-8 and noggin, have been defined that can completely rescue UV-ventralized embryos, such that a normal animal is formed (Smith and Harland 1991; Sokol et al. 1991). Wnt proteins are secreted, but only very locally, remaining confined to the plasma membrane and extracellular matrix of the secreting cell and of cells immediately adjacent. Xwnt-8 can apparently induce a N.C. because a complete $D / V$ axis is restored even when a lineage tracer coinjected with $X w n t-8$ RNA is confined to presumptive gut endoderm, with no contribution to the dorsal mesoderm (Smith and Harland 1991). Injection of Xwnt-8 RNA into ventral vegetal blastomeres of normal embryos causes duplication of dorsal axial structures, whereas injection into dorsal vegetal blastomeres of normal embryos has no effect (Sokol et al. 1991; Smith and Harland 1991). Thus $X w n t-8$ has the characteristics of a factor that would normally be activated in dorsal regions by the corticocytoplasmic rotation. However, Xwnt-8 RNA is not present in fertilized eggs; rather, this gene is first expressed at early gastrula stages and then ventrally /Christian et al. 1991; Smith and Harland 1991). Moreover, $X w n t-8$ RNA is highly induced in embryos ventralized by UV irradiation (Smith and Harland 1991). It was therefore postulated that a maternally expressed Xwnt gene would perform a similar function. In encouraging support of these postulates, M. Ku and D. Melton (pers. comm.) have isolated such a gene, which they have named Xwnt-9. Another gene with similar activity to $X w n t-8$ is noggin, which encodes a novel secreted factor and was cloned (as was $X w n t-8$ ) by an elegant functional screen that assayed for rescue of UV-ventralized embryos (Smith and Harland 1992). Noggin is expressed maternally, and along with Wnt proteins, is an excellent candidate for an activity required for the formation of the N.C.

On the basis of these data, it is plausible to suggest that after the corticocytoplasmic rotation, noggin and Wnt function is activated on the dorsal side of the embryo, in vegetal regions, and as will be discussed, also in the marginal zone and animal cap (Fig. 1). A conundrum remains, as no Wnt or noggin RNAs are asymmetrically distributed during early cleavage, before the onset of zygotic transcription; although, functional Wnt or Noggin protein may be localized.

\section{Wnt genes and noggin potentiate the ability of activin and FGF to induce dorsal mesoderm}

Xwnt-8 is not able to induce a secondary axis when injected into the animal pole, indicating that it requires vegetally localized factors for its action (Smith and Harland 1991; Sokol et al. 1991). These factors may be the soluble mesoderm-inducing factors of the activin and FGF families (see below) because in an animal cap assay, $X w n t-8$ greatly enhances the ability of these factors to induce dorsal and lateral mesoderm (muscle and notochord, respectively) (Christian et al. 1992; Sokol and Melton 1992), whereas noggin enhances induction by activin (the effects of noggin on FGF-mediated induction are not known) (Smith and Harland 1992). Wnt genes and noggin are therefor: in an interesting class of induction potentiators. Interestingly, a similar potentiation of induction by FGF and activin has been observed in animal caps isolated from embryos treated with $\mathrm{LiCl}$ soon after the 32-cell stage (Slack et al. 1988; Cooke et al. 1989; Kao and Elinson 1989). The net result of lithium treatment is symmetric formation of dorsal mesoderm around the entire circumference of the marginal zone (Kao and Elinson 1988). The effects of lithium may be mediated by perturbing the phosphoinositide cycle (Busa and Gimlich 1989|, but the connection between this observation, Wnt/noggin action, and normal D/V patterning is unclear (see Olson et al. 1991).

\section{Activin, FGF, and BMP-4 are mesoderm inducers}

Several soluble growth factors are able to induce dorsal and ventral mesoderm in animal cap assays and are expressed in the early embryo. The precise spectrum of mesodermal derivatives that they can induce is somewhat assay dependent (Table 1), but consistent conclusions emerge. Activins are members of the TGF- $\beta$ family that are able to induce extensive dorsal mesoderm, including notochord and neural-inducing tissue (see Smith 1989; Thomsen et al. 1990; Green et al. 1992). At low concentration, activins are also able to induce ventral mesoderm, characterized by mesenchyme /Green et al. 1990). Injection of activin A RNA into vegetal or marginal zone cells of UV-treated embryos can restore a partial dorsal axis, but no head tissue is formed (Thomsen et al. 1990; Sokol et al. 1991). Consistent with this, activin RNA injected into ventral vegetal blastomeres of normal embryos is able to induce only a partial axis consisting of posterior structures (in contrast to $X w n t-8$, which induces a complete secondary axis|, whereas introduction of activin RNA into dorsal vegetal blastomeres produces an embryo with a duplicated tail. The inability of activin to induce a complete secondary axis is consistent with the idea that Wnt genes or noggin potentiate its action in vivo. The egg contains numerous activin-like factors (Asashima et al. 1991; G.D. Guex and J.C. Smith; D.A. Melton; both pers. comm.) but apparently no activin RNAs, suggesting that activin protein may be imported from the surrounding follicle cells. Important support for a key role of activin in mesoderm induction has been obtained by Hemmati-Brivanlou and Melton (1992), because introduction into fertilized eggs of a dominantnegative activin receptor [lacking the cytoplasmic serine-threonine kinase domain (Attisano et al. 1992)] can prevent, in a large percentage of embryos, formation of any recognizable mesoderm, either dorsal or ventral. This striking result implies that activin-like molecules are required for an early step in both dorsal and ventral mesoderm induction. It also indicates that in whole embryos, endogenous FGFs are unable to substitute for activins. Intriguingly, animal caps isolated from embryos expressing the dominant-negative activin receptor still respond to basic FGF (bFGF) in vitro and express mesodermal markers, further confirming that the animal cap 
Table 1. Summary of mesoderm-inducing effects of various factors

\begin{tabular}{|c|c|c|c|c|c|}
\hline Assay & Activin & FGF & BMP-4 & Xwnt-8 & noggin \\
\hline $\begin{array}{l}\text { Animal cap assay } \\
\text { (incubation in } \\
\text { factor) }\end{array}$ & $\begin{array}{l}\text { concentration-dependent } \\
\text { response. }{ }^{1} \text { High } \\
\text { concentrations: } \\
\text { notochord, muscle, } \\
\text { neural tissue. Low } \\
\text { concentrations: blood, } \\
\text { mesenchyme. } \\
\text { Difference in response } \\
\text { of dorsal and ventral } \\
\text { caps more pronounced } \\
\text { in larger caps. }{ }^{2} \text { Ventral } \\
\text { caps do not express } \\
\text { anterior neural } \\
\text { markers. }{ }^{3}\end{array}$ & $\begin{array}{l}\text { concentration-dependent } \\
\text { response. Some muscle, } \\
\text { mesenchyme, } \\
\text { proctodeum. }{ }^{1,8} \\
\text { Difference in response } \\
\text { of dorsal and ventral }^{\text {cap. }}{ }^{\text {. Dorsal caps }} \\
\text { develop melanocytes; }^{\text {velal caps do not. }}\end{array}$ & $\begin{array}{l}\text { no obvious } \\
\text { mesoderm but } \\
\text { weak Xhox3 } \\
\text { induction. }{ }^{11}\end{array}$ & no soluble protein & $\begin{array}{l}\text { no mesoderm } \\
\text { induction }^{16}\end{array}$ \\
\hline $\begin{array}{l}\text { Animal cap assay }{ }^{\mathrm{b}} \\
\text { (RNA injection and } \\
\text { explant) }\end{array}$ & $?$ & $\begin{array}{l}\text { induces more dorsal } \\
\text { mesoderm than } \\
\text { incubation in soluble } \\
\text { factor. }{ }^{10} \text { Some } \\
\text { difference in response of } \\
\text { dorsal and ventral cap. } \\
\text { Dorsal caps: some } \\
\text { notochord, muscle; } \\
\text { some neural tissue. } \\
\text { Ventral caps: } \\
\text { mesenchyme. }\end{array}$ & $\begin{array}{l}\text { induces ventral } \\
\text { mesoderm } \\
\text { including } \\
\text { mesenchyme, } \\
\text { possibly } \\
\text { blood. }^{11-13} \\
\text { Inhibits activin; } \\
\text { no effect on } \\
\text { FGF. }{ }^{11,12}\end{array}$ & $\begin{array}{l}\text { caps }>50 \% \text { animal } \\
\text { hemisphere express } \\
\text { muscle actin; small } \\
\text { caps do not. }{ }^{5,9} \text { Response } \\
\text { dependent on time of } \\
\text { application. Pre-MBT: } \\
\text { potentiates activin, } \\
\text { FGF., } .^{914} \text { Post-MBT: } \\
\text { inhibits activin, FGF. }{ }^{15}\end{array}$ & $\begin{array}{l}\text { potentiates } \\
\text { activin. }{ }^{16} \\
\text { FGF? }\end{array}$ \\
\hline $\begin{array}{l}\text { Einsteck }^{c} \\
\text { (after animal cap } \\
\text { incubation) }\end{array}$ & $\begin{array}{l}\text { complete } 2^{\circ} \text { axis in } \\
\text { normal host }\end{array}$ & tail only ${ }^{4}$ & $\begin{array}{l}\text { tail-like, but no } \\
\text { neural tube }{ }^{11}\end{array}$ & $?$ & $?$ \\
\hline $\begin{array}{l}\text { Whole embryo assay } \\
\text { (RNA injection) } \\
\text { into }\end{array}$ & & & & $\begin{array}{l}\text { Response dependent on } \\
\text { time of application. }\end{array}$ & \\
\hline animal cell & no effect ${ }^{5}$ & no effect ${ }^{1}$ & ventralizes $^{11,12}$ & $\begin{array}{l}\text { pre-MBT: no effect. }^{5} \\
\text { post-MBT: ? }\end{array}$ & $?$ \\
\hline dorsal vegetal cell & tail duplication ${ }^{5}$ & ? & ventralizes $^{11}$ & $\begin{array}{l}\text { pre-MBT: no effect } \\
\text { post-MBT: ventralizes }{ }^{14}\end{array}$ & $?$ \\
\hline ventral vegetal cell & no effect ${ }^{5}$ & ? & $\begin{array}{l}\text { mild } \\
\text { ventralization }{ }^{11}\end{array}$ & $\begin{array}{l}\text { pre-MBT: complete } 2^{\circ} \\
\text { axis }{ }^{16} \\
\text { post-MBT: no effect }{ }^{15}\end{array}$ & $?$ \\
\hline UV vegetal cell & $\begin{array}{l}\text { Posterior axis only } \\
\text { induced }^{6}\end{array}$ & $?$ & $?$ & $\begin{array}{l}\text { pre-MBT: complete axial } \\
\text { rescue. }{ }^{6} \text { post-MBT: ? }\end{array}$ & $\begin{array}{l}\text { complete axial } \\
\text { rescue }^{16}\end{array}$ \\
\hline $\begin{array}{l}\text { Whole embryo assay } \\
\text { (protein injection) }\end{array}$ & $\begin{array}{l}\text { into blastocoel. }{ }^{7} \text { Ectopic } \\
\text { mesoderm induction. } \\
\text { Into blastomeres. }{ }^{7} \text { No } \\
\text { effect. }\end{array}$ & $\begin{array}{l}\text { into blastocoel. } .^{7} \text { Ectopic } \\
\text { mesoderm forms later } \\
\text { than for activin. }\end{array}$ & $?$ & $?$ & $?$ \\
\hline
\end{tabular}

${ }^{2}$ Animal caps were removed from blastula stages and incubated in saline with added factor. Differentiation was scored several hours later.

bRNAs encoding various factors were injected into the animal hemisphere at the one-cell stage; animal caps were isolated at blastula stages, incubated in neutral saline (with or without additional factors), and assayed later for differentiation.

cThe Einsteck assay analyzes the ability of a piece of tissue to induce an axis after implantation into the blastocoel of a host embryo. This analysis may determine whether tissue has organizer activity. In the assays quoted, the ability of various factors to induce an organizer was determined after incubation of the animal cap with factor, and implantation of the treated cap at the equivalent of early gastrula.

dRNA for various factors was injected into embryos from fertilization until the 32-cell stage, either into animal cap or vegetal hemisphere cells of normal embryos, or into the vegetal hemisphere of UV-irradiated (ventralized) embryos. Intact embryos were later scored for induction of a secondary axis, suppression of normal axis formation (ventralization) or, in the case of UV-treated animals, for restoration of a normal axis. In the case of Xwnt-8, expression after the MBT was effected by expression of a DNA construct, whose promoter is activated at the MBT.

ePurified protein was injected into the blastocoel or into blastomeres of early blastulae, and embryos were later scored for ectopic mesoderm induction. References: ${ }^{1}$ Green and Smith (1990); Green et al. (1992). ${ }^{2}$ Sokol and Melton (1991). ${ }^{3}$ Bolce et al. (1992). ${ }^{4}$ Ruiz i Altaba and Melton (1989a). ${ }^{5}$ Sokol et al. (1991). ${ }^{6}$ Smith and Harland (1991). ${ }^{7}$ Cooke et al. (1989). ${ }^{8}$ Green et al. (1990). ${ }^{9} \mathrm{Christian}$ et al. (1992). ${ }^{10}$ Kimelman and Maas (1992). ${ }^{11}$ Jones et al. (1992). ${ }^{12}$ Dale et al. (1992). ${ }^{13}$ Koster et al. (1991). ${ }^{14}$ Sokol and Melton (1992). ${ }^{15}$ Christian and Moon (this issue). ${ }^{16}$ Smith and Harland (1992).

assay is not a complete reflection of the response of an intact embryo (Hemmati-Brivanlou and Melton 1992).

The egg contains several forms of FGF that are all able to induce dorsolateral (muscle) and some ventral (mesenchyme) mesodermal cell types when applied in soluble form to animal caps (Kimelman et al. 1988, 1992; Slack and Isaacs 1989; for review, see Kimelman et al. 1992). Posterior mesoderm, including a proctodeum (the common opening of the urogenital and alimentary tracts), is also induced (Ruiz i Altaba and Melton 1989a; Cho and De Robertis 1990; Green et al. 1990, 1992). However, when high levels of RNA encoding bFGF are injected 
into the animal hemisphere of fertilized eggs, isolated animal caps form significant amounts of notochord (i.e., dorsal mesoderm), suggesting that in whole embryos FGF may contribute to dorsal mesoderm formation (Kimelman and Maas 1992; see also Thompson and Slack 1992). This is supported by the effects of expressing a dominant-negative FGF receptor during embryogenesis-posterior regions of the embryo, including dorsal regions, are perturbed (Musci et al. 1990; Amaya et al. 1991). Embryos expressing this construct have surprisingly normal heads, further suggesting that FGF acts later than activin during normal mesoderm induction or that activin can substitute for FGF. A later time for FGF action is also supported by the demonstration that FGF protein is concentrated in the marginal zone (Shiurba et al. 1991), rather than in the inducing vegetal cells. Using an animal cap assay, it is clear that activin and FGF can induce several similar tissues, suggesting that their action in whole embryos is mediated by pathways that coincide downstream of initial receptor binding. This overlap may include Ras function (or that of a related protein) because dominant-negative Ras constructs prevent mesoderm induction by either activin or FGF (Whitman and Melton 1992).

Another member of the TGF- $\beta$ family, BMP-4, or DVR-4, may play a role in ventral mesoderm induction. As soluble protein, BMP-4 does not induce morphologically recognizable mesoderm; however, animal caps isolated from embryos injected with BMP-4 RNA form a ventral mesodermal tissue, mesenchyme, and express the ventral mesodermal markers $X h o x 3$ and globin (Koster et al. 1991; Dale et al. 1992; Jones et al. 1992). BMP-4 RNA is apparently localized uniformly in the embryo.

The current data therefore suggest that activin is required for induction of both dorsal and ventral mesoderm during the initial stages of mesoderm formation, that FGFs act later and induce dorsal, lateral, and ventral mesoderm, particularly posterior mesoderm, and BMP-4 may be involved in ventral mesoderm induction (Fig. 1). Employing in vitro (animal cap) assays, Green et al. (1992) have shown that induction of different kinds of mesoderm is exquisitely sensitive to concentration of activin and FGF (see Table 1). These investigators have suggested that orthogonal gradients of activin and FGF may be sufficient to specify the major axial coordinates. However, the potentiation of activin- and FGF-mediated induction by Wnt genes and noggin suggests that in the embryo, concentration gradients of activins and FGFs may be substituted by or sharpened by gradients of Wnt or noggin activity.

\section{The Spemann organizer, ventral mesoderm, and the three-signal model}

Dorsal mesoderm (presumptive head mesoderm and notochord) comprises an arc of $\sim 60^{\circ}$ around the marginal zone and is the tissue that Spemann called the organizer, because it would induce a secondary axis when implanted into a host embryo (Spemann 1938; Stewart and Gerhart 1990). Although the N.C. and the organizer can both restore a normal axis to UV-treated animals or can induce a secondary axis in normal embryos, they are distinct in many ways. First, while N.C. cells contribute largely to gut endoderm, the marginal zone organizer gives rise exclusively to mesodermal tissues, including notochord, head mesoderm, and muscle. Second, while the N.C. can induce formation of notochord in the extreme ventral marginal zone, the organizer is unable to do so (Dale and Slack 1987b; Stewart and Gerhart 1990). Third, while the N.C. is fully active by the 32 -cell stage, the organizer acquires significant activity only after the MBT and the onset of zygotic transcription /see Nieuwkoop 1973; Gimlich 1986). Consistent with this, Nakamura and colleagues (1970) demonstrated that dorsal marginal zone (DMZ) cells isolated at the 32-cell stage failed to differentiate into notochord and muscle. However, from the 128-cell stage, cultured DMZ formed extensive notochord and muscle in vitro, reaching a plateau by late blastula.

\section{The three-signal model: the organizer dorsalizes ventral mesoderm ...}

$\mathrm{D} / \mathrm{V}$ patterning in the marginal zone occurs in several steps. This became apparent after a comparison of the fate map and the in vitro-differentiated fate, or specification of marginal zone isolated before the MBT. Although lateral marginal zone is destined to form muscle, this region forms very little muscle in culture when isolated during early blastula stages. Conversely, isolated dorsal marginal zone forms extensive muscle (as well as notochord) (Yamada 1950; Nieuwkoop 1973; Smith and Slack 1983; Cooke and Webber 1985; Dale and Slack 1987b). By the onset of gastrulation, however, isolated lateral marginal zone will differentiate into muscle, as the fate map implies.

Using individual vegetal blastomeres from 32-cell embryos as inducer and animal caps of similar age as responder tissue, Dale and Slack (1987b) showed that the vegetal blastomeres displayed only two inducing capacities: dorsal induction of both muscle and notochord, and ventral induction of mesenchyme and blood. In these assays no vegetal blastomeres induced just lateral mesoderm (i.e., muscle, without notochord). Similar results had been obtained by Nieuwkoop and Boterenbrood, primarily in urodele amphibians (newts and salamanders) (see Nieuwkoop 1973). These workers suggested that although a $\mathrm{D} / \mathrm{V}$ gradient of inducing potential was present in the vegetal endoderm of the embryo, this gradient was somehow lost in isolated tissue. An alternate model was presented in the three-signal hypothesis (Smith and Slack 1983; Dale and Slack 1987b). This model holds that normally, vegetal cells can induce only two kinds of mesoderm-dorsal and ventral-and that formation of lateral mesodermal cell types requires a third signal, emitted from the dorsal marginal zone (organizer) in late blastula and gastrula. This third signal dorsalizes more ventral marginal zone to induce lateral mesoderm (muscle and lateral plate) (Fig. 2). 
THE THREE SIGNAL MODEL

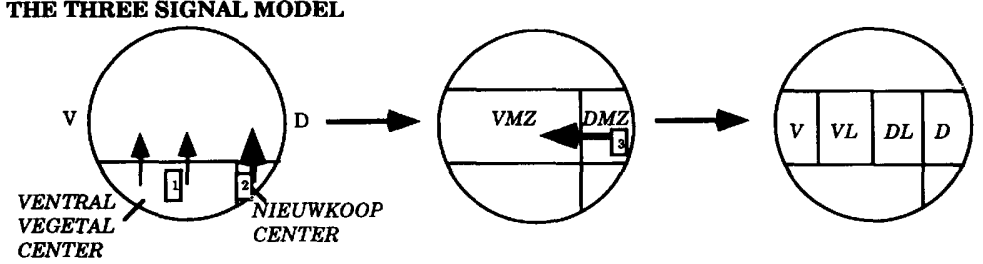

A FOUR SIGNAL MODEL

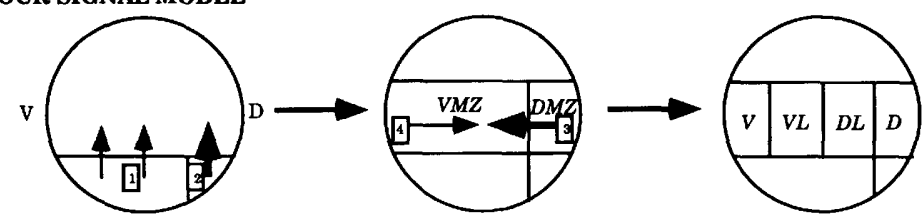

Figure 2. Modification of the three-signal model as proposed by Dale and Slack (1987b) and Smith and Slack (1983). During early cleavage, dorsal- and ventralinducing centers are set up in the vegetal endoderm and induce mesoderm in overlying equatorial cells or marginal zone (the first and second signals of the model). The dorsal vegetal center (also called the N.C.) induces the dorsal marginal zone (DMZ) to form presumptive notochord and muscle and comprises a small sector of the marginal zone. The ventral marginal zone (VMZ) includes a large region (laterally, abutting the DMZ) that is destined to form muscle, but that by mid-blastula, is not capable of differentiating into muscle when removed from the embryo. By early gastrula, however, this region [ventrolateral (VL) and dorsolateral (DL) marginal zone] will differentiate as muscle in isolation. Various assays have shown that the DMZ lalso called the organizer) is capable of inducing muscle in the VMZ, which leads to the proposal that a third signal, emanating from the DMZ, induces lateral mesoderm in the VMZ, implying a passive role for the VMZ. Dorsolateral marginal zone (DL) will form muscle and some notochord; ventrolateral marginal zone (VL) will form some muscle and lateral plate. Activin and FGF, probably in conjunction with Xwnt-9 or noggin, are likely candidates for dorsalizing signals. In the four-signal model, proposed from the data summarized in this review, the VMZ emits ventralizing signals, which may include $X$ wnt-8 in conjunction with BMP-4, possibly retinoids, and possibly FGF that modulates the dorsalizing signal. These ventralizing forces may prevent the spread of the dorsalizing signal to extreme ventral regions and sharpen a gradient of dorsalizing signals. Ventralizing signals may not be emitted from a restricted region of the $\mathrm{VMZ}$ as drawn but may be generally present in this region.

The induction of more lateral mesoderm (muscle) in ventral marginal zone (VMZ) by DMZ organizer was observed by Spemann and Mangold (see Spemann 1938) and was analyzed in vitro by Yamada (see Yamada 1950), who may have coined the term dorsalization. More recently, several clear demonstrations of dorsalization have been provided both by in vitro recombination assays and by organizer transplantation into a host embryo (Smith and Slack 1983; Dale and Slack 1987b; Stewart and Gerhart 1990; for review, see Smith 1989).

\section{but ventralizing forces can inhibit dorsal signals}

The three-signal model implied that after its initial induction, ventral mesoderm waited passively for reprogramming by a dorsalizing signal. In support of this, it is clear that dorsalizing signals are dominant to ventralizing signals in the assays described above. A new theme to emerge, however, is that active ventralizing forces may modulate the dorsal phenotype. Active ventralization was suggested by the demonstration that injection of BMP-4 RNA into dorsal blastomeres during early cleavage ventralizes embryos, which develop without notochord and head tissue (Dale et al. 1992; Jones et al. 1992). This RNA has no effect when injected ventrally. Interestingly, animal caps isolated from these embryos are resistant to induction by activin, but not by FGF. This is apparently not a result of simple competition for activin receptor occupancy, because BMP-4 binds the activin receptor very poorly (Attisano et al. 1992). Because BMP-4 RNA is present in both eggs and after the MBT, it is not clear when this factor exerts its effects.

Corroborative data arise from an insightful analysis of normal Xwnt-8 function (Table 1; Christian and Moon, this issue). Xwnt-8 is not normally expressed until gas- trula stages and, then, on the ventral side of the embryo. Expression of Xwnt-8 after the MBT (from a DNA expression construct) in the $\mathrm{DMZ}$ ventralizes the embryo, preventing both notochord and head formation. Late $X$ wnt-8 expression on the ventral side has little effect. This is precisely the opposite result of Xwnt-8 expression (by RNA injection) soon after fertilization, as described above (Smith and Harland 1991; Sokol et al. 1991). Similarly, while expression of Xwnt-8 protein (after RNA injection), before the MBT, enhances mesoderm induction in animal caps isolated and then treated with FGF or activin (Christian et al. 1992; Sokol and Melton 1992), expression after the MBT prevents induction of dorsal mesoderm (Christian and Moon, this issue). The altered response of animal cap and marginal zone cells to ectopic Xwnt-8 during development is an extraordinary demonstration of the changes in competence to respond to the same ligand that embryonic regions undergo and is not understood at the molecular level.

An additional ventralizing force during embryogenesis may include retinoids. Retinoic acid has profound effects on the determination of many embryonic tissues, including mesoderm and ectoderm (Durston et al. 1989; Sive et al. 1990; Ruiz i Altaba and Jessel 1991). While the major effect of retinoids is the disruption of anteroposterior patterning, retinoids are also able to decrease the inducing capacity of dorsal mesoderm and, possibly, increase the amount of some (but clearly not all) ventral mesodermal derivatives (Ruiz i Altaba and Jessel 1991; Sive and Cheng 1991). The presence of RNAs encoding retinoid receptors in the unfertilized egg (Blumberg et al. 1992) supports the notion that retinoids may play an early role in axial patterning.

Although, collectively, these data strongly suggest that active ventralizing signals operate during normal 
embryogenesis, one puzzle that remains is the failure to detect ventralization of $\mathrm{DMZ}$ by $\mathrm{VMZ}$ in conjugation analyses (e.g., Smith and Slack 1983; Dale and Slack $1987 \mathrm{~b})$. One possibility is that endogenous ventralizing signals are not normally able to counteract strong dorsalizing signals from the organizer but only operate where dorsalizing influence is less strong, on more lateral tissue. The prediction, then, is that if conjugated to dorsolateral marginal zone, VMZ would depress expression of more lateral mesodermal markers.

\section{$A$ revised three-signal model: four signals?}

The intial molecular model of the three-signal hypothesis clearly needs revision and, perhaps, reformulation into a four-signal model (Fig. 2). Conceptually, the most important revision must be a rethinking of the role of ventral signals in $\mathrm{D} / \mathrm{V}$ patterning. The results discussed above imply that dorsalization may have a ventralization counterpart that may be required to position $\mathrm{D} / \mathrm{V}$ boundaries and to stop the spread of dorsalization. This ventralization may involve BMP-4, Xwnt-8 and possibly retinoids and occurs subsequent to intial induction of DMZ and VMZ by the vegetal inducing centers. High concentrations of activin, perhaps in conjunction with FGF and an induction potentiator such as a Wht gene or noggin, remain good candidates for dorsalizing forces. A continuing theme in the marginal zone, then, is a role for Wnt genes in defining both dorsal and ventral regions, through the action of these genes after the MBT and the onset of zygotic transcription (Fig. 1).

\section{$\mathrm{D} / \mathrm{V}$ asymmetry in the animal cap}

The $\mathrm{D} / \mathrm{V}$ pattern extends into the presumptive ectoderm that comprises the animal hemisphere (Fig. 1). At least part of this patterning occurs soon after the corticocytoplasmic rotation, because at the eight-cell stage isolated ventral, but not dorsal, animal blastomeres go on to express the Epi-1 antigen, whose epitope is restricted to epidermis (a ventral ectodermal derivative) (Savage and Phillips 1989). Consistent results have been obtained by transplantation to ectopic sites of dorsal and ventral animal blastomeres at the 16- and 32-cell stages; whereas dorsal cells often differentiate according to their original position, ventral animal blastomeres aquire the fate of surrounding tissues (Gallagher et al. 1991).

Sokol and Melton (1991) showed that at early blastula, dorsal animal caps are induced more easily by activin $\mathrm{A}$ than are ventral caps to form dorsal mesoderm and ectodermal derivatives (eyes, cement gland, neural tissue) presumably induced by this dorsal mesoderm. This is most obvious using large caps; however, some $\mathrm{D} / \mathrm{V}$ differences have been observed with smaller caps and induction with both activin and FGF (Bolce et al. 1992; Christian et al. 1992). The asymmetry may be controlled, in part, by (you guessed it) a Wnt gene, because $\mathrm{D} / \mathrm{V}$ differences in response to FGF or activin can be abolished by introduction of Xwnt-8 RNA into the ani- mal hemisphere of embryos within the first few cell divisions (Christian et al. 1992; Sokol and Melton 1992).

By the early gastrula stage an additional level of $D / V$ patterning is present in the animal cap. This is manifest by enhanced competence of dorsal over ventral cells for induction to ectodermal derivatives (including neural tissue and cement gland) in response to dorsal mesoderm (organizer) (Sharpe et al. 1987; Otte et al. 1991). The differential competence is mirrored by higher levels of the protein kinase $\mathrm{C} \alpha$ isozyme (PKC $\alpha$ ) in dorsal than in ventral animal cap cells and can be equalized by the expression of PKCa ventrally (Otte and Moon 1992a). In this case, Xwnt-8 RNA injection into the animal pole does not alter differences in $\mathrm{D} / \mathrm{V}$ competence for neural induction, whereas injection of Xwnt-8 RNA into the VMZ does (Otte and Moon 1992b). This asymmetry may therefore be an indirect consequence of enhanced Wnt activity in the marginal zone-which causes the release, or enhances the action of another signal that diffuses through the ectodermal plane - and, possibly through activation of PKC $\alpha$ dorsally, changes ectodermal competence for neural induction.

Suggestive new data stem from analysis of embryos expressing a dominant-negative activin receptor (Hemmati-Brivanlou and Melton 1992). Although expression of mesodermal markers is essentially absent in these embryos, high levels of dorsal ectodermal markers are expressed, including genes expressed in neural tissue and cement gland. Because these genes appear normally to require mesodermal signals for induction, the data suggest that activins may play a role in suppressing the potential of ectodermal (animal cap) cells to assume dorsal fates (neural tissue and cement gland).

The data suggest therefore that $\mathrm{D} / \mathrm{V}$ differences in the animal hemisphere are (at least) twofold. An early difference may be caused directly by dorsally restricted Wnt gene activity in the animal hemisphere and may enhance the induction of dorsal mesoderm by activin or FGF while another, later, difference in the competence of ectoderm to become neural tissue is an indirect result of Wnt (or perhaps, noggin) activity in the marginal zone (Fig. 1).

\section{The early $D / V$ pattern is labile}

The $\mathrm{D} / \mathrm{V}$ axis is initially labile. This is implicit in the ability to restore a dorsal axis to UV-ventralized embryos or to induce a secondary axis in normal animals by N.C. or organizer implant, or by expression of Wnt genes or noggin. These data show that both in the marginal zone and animal cap regions ventral tissue is not irrevocably determined even by early gastrula stages. Conversely, dorsal regions are also labile and can be converted to more ventral tissue by ectopic expression of Xwnt-8 in early gastrula or by injection into the blastocoel of reagents that prevent gastrulation movements /Gerhart et al. 1989|. The three (plus!)-signal model suggests that this lability is prerequisite for refining an initially crude $\mathrm{D} / \mathrm{V}$ pattern to allow induction of lateral mesoderm. Furthermore, this lability would allow the embryo to devise 
various checkpoints, where incorrect patterning could be recognized and rectified.

\section{Remembering induction}

Early patterning takes place without new transcription

A great deal of $\mathrm{D} / \mathrm{V}$ patterning takes place before $\mathrm{MBT}$ and the onset of zygotic transcription. Thus, in the absence of new transcription, the N.C. forms and loses its ability to restore a dorsal axis, mesoderm induction begins, and the animal cap aquires $\mathrm{D} / \mathrm{V}$ asymmetry. What is the molecular nature of these memories? The data described here suggest that dorsal activation of a Wnt gene or noggin soon after fertilization could serve as a dorsal memory. However, because neither noggin nor any known Wnt RNA is asymmetrically distributed during early cleavage, asymmetric function of these genes may be controlled at the translational or post-translational level, as future analyses will tell. Equally plausible, is the specific activation (or repression) of a pathway downstream of or parallel to Wnt or noggin secretion, such as asymmetric distribution of a receptor for these proteins, asymmetric distribution of signal transduction machinery, or obviously, dorsal restriction of some unrelated gene product.

\section{Genes expressed after the MBT define domains in the marginal zone}

By early gastrula, in the three or so hours that have passed since the onset of zygotic transcription, a large number of new transcripts has appeared in the marginal zone. By induction assays and analyses of lineage commitment, four domains have been defined in the marginal zone at this stage: the dorsal organizer, a dorsolateral zone that includes presumptive muscle and can also be induced to form notochord by organizer, a ventrolateral region (including presumptive muscle and lateral plate), and a ventral region (Dale and Slack 1987b; Stewart and Gerhart 1990). Have any genes been isolated that provide molecular correlates for these domains? To some extent, yes. Within the marginal zone, three patterns of early gene expression have emerged: restriction to the organizer, restriction to ventrolateral marginal zone, and expression throughout the marginal zone. Although the number of genes analyzed is small, no genes with expression restricted to lateral or ventral regions in early gastrula have been found, indicating that induction of these regions is not complete. Many of the genes expressed in the early gastrula marginal zone encode potential regulatory products and are induced as an immediate early response to growth factors, that is, in the absence of protein synthesis and very soon (within minutes) after growth factor application.

Although noggin RNA is unlocalized in the fertilized egg and early embryo, by late blastula/early gastrula, this RNA is localized exclusively in the DMZ, or presumptive organizer, probably owing to new transcription and degradation of the maternal mRNA /Smith and Harland
1992). Xwnt-9 mRNA is predominantly localized in the vegetal hemisphere of four- to eight-cell embryos, but by late blastula/early gastrula this RNA is present at higher levels dorsally (M. Ku and D. Melton, pers. comm.). The factors that regulate localized noggin and Xwnt-9 expression have not been defined. Another set of transcripts, all inducible as an immediate early response to high concentrations of activin, but not FGF, is also localized in the DMZ. These include FKH-1 la forkhead family member) (Dirksen and Jamrich 1992), Xlim-1 (Taira et al. 1992), and goosecoid (Cho et al. 1991). All contain homeo domains and are therefore potential regulators of organizer function. goosecoid RNA injected into the VMZ is capable, in some embryos, of inducing a partial secondary axis (Cho et al. 1991).

Two genes have been defined that are expressed throughout both lateral and VMZ. By early gastrula $X w n t-8$ RNA is restricted to ventrolateral regions, which exclude the organizer and, therefore, the domain of noggin expression (Smith and Harland 1991, 1992). Again, factors regulating $X w n t-8$ expression have not been defined. The $X M Y O D$ gene is a member of the myogenic family of DNA-binding proteins (Hopwood and Gurdon 1990). Soon after MBT, XMYoD RNA is ubiquitously expressed (Rupp and Weintraub 1991); but by early gastrula, both protein and RNA are restricted to the VMZ and lateral marginal zone, including regions that are not fated to form muscle (Frank and Harland 1991; Harvey 1992). During neurula stages, $X M y o D$ expression becomes somite specific (i.e., restricted to dorsolateral marginal zone derivatives) (Hopwood et al. 1989; Harvey 1990; Frank and Harland 1991). In animal caps XMyoD is inducible by both FGF and activin (Hopwood et al. 1989).

The Xenopus homolog of the murine Brachyury gene, $\mathrm{Xbra}$, is expressed around the entire circumference of the marginal zone in early gastrula (Smith et al. 1991; Cunliffe and Smith 1992). Xbra is induced as an immediate early response to both FGF and activin in animal caps and is clearly an important regulatory gene, because it can induce ectopic mesoderm after RNA injection into animal caps (Cunliffe and Smith 1992). In older embryos, Xbra expression becomes restricted to posterior mesoderm and notochord. A gene similar to the Drosophila snail gene, which plays a major role in mesoderm formation in flies, is Xsna, which is expressed in both DMZ and VMZ at early gastrula (Sargent and Bennet 1990).

Although retinoids can enhance expression of many genes in Xenopus embryos, only three genes have been defined that are induced by retinoids alone in an animal cap assay. All are homeo domain genes: Xlim-1, Xhox.lab1, and Xhox.lab2 (Sive and Cheng 1991; Taira et al. 1992; H. Sive, unpubl.). As discussed above, Xlim-1 is also induced by activin and is expressed in the DMZ of early gastrulae, a pattern of expression that is not consistent with the proposed role for retinoids in ventral patterning (Ruiz i Altaba and Jessell 1991). As yet, no data indicate whether endogenous retinoids induce these genes.

A plethora of additional putative regulatory genes, whose precise localization at early gastrula is unknown, 
is expressed from the zygotic genome soon after MBT. These include several homeo domain genes, including Xhox3, which is induced in animal caps by FGF or low concentration of activin and, at later stages, is restricted to ventral and posterior mesoderm. This gene appears to play a key role in anteroposterior axis formation (Ruiz i Altaba and Melton 1989a,b). Mix-1 is a homeo domain gene expressed in both endoderm and mesoderm and is induced as an immediate early response to activin (Rosa 1989). Several additional homeo domain genes are expressed in the dorsal blastopore lip, where their precise localization is not known, and may play a later role in organizer function (Blumberg et al. 1991). Additionally, activin B (Thomsen et al. 1990) and several FGFs (Tannahill et al. 1992; see Kimelman et al. 1992) are also expressed after MBT. Many genes that are expressed as maternal RNAs and appear to be key regulators of early $\mathrm{D} / \mathrm{V}$ patterning are also expressed from the zygotic genome much later in development, suggesting a continuing role in axial patterning.

\section{Perspective}

In this review I have concentrated on describing the phenomenology and the possible molecular basis for some of the early events in Xenopus axial patterning. Over the past year, Wnt genes and a new candidate, noggin, have emerged as possible determinants of dorsal axial position. The challenge now is to define whether genes that can act as dorsal determinants, when ectopically expressed, normally do so. Soluble growth factors, particularly activin and members of the FGF family appear to play a major role in both dorsal and ventral mesoderm induction. Dorsally, mesoderm induction takes place in conjunction with Wnt proteins and Noggin. Ventrally, the embryonic marginal zone has emerged as more active, with the description of a ventralizing growth factor, BMP-4, and, interestingly, a Wnt gene (Xwnt-8) with similar effects. With the growing appreciation for conservation of developmental strategies in different organisms, developmental biology is becoming system directed rather than organism directed. The promise that the genes and cell interactions defined in Xenopus will have piscean, avian, and mammalian counterparts will certainly fuel and direct developmental analysis over the next few years.

\section{Acknowledgments}

I thank Richard Harland, Andrew Lassar, Rudolf Jaenisch, David Kimelman, Min Ku, Doug Melton, Jim Smith, and Hal Weintraub for-discussion and comments; and Michael Danilchik, Mary Lou King, Doug Melton, Randall Moon, and Jim Smith for communicating data before publication.

\section{References}

Amaya, E., T.J. Musci, and M.W. Kirschner. 1991. Expression of a dominant negative mutant of the FGF receptor disrupts mesoderm formation in Xenopus embryos. Cell 66: 257269.

Asashima, M., H. Nakano, H. Uchiyama, H. Sugino, T. Nakamura, Y. Eto, D. Ejima, S.-I. Nishimatsu, N. Ueno, and K. Kinosha. 1991. Presence of activin (erythroid differentiation factor) in unfertilized eggs and blastulae of Xenopus laevis. Proc. Natl. Acad. Sci. 88: 6511-6514.

Attisano, L., J.L. Wrana, S. Cheifetz, and J. Massague. 1992. Novel activin receptors: Distinct genes and alternative mRNA splicing generate a repertoire of serine/threonine kinase receptors. Cell 68: 97-108.

Blumburg, B., C.V.E. Wright, E.M. De Robertis, and K.W.Y. Cho. 1991. Organizer-specific homeobox genes in Xenopus laevis embryos. Science 253: 194-196.

Blumberg, B., D.J. Mangelsdorf, J.A. Dyck, D.A. Bittner, R.M. Evans, and E.M. De Robertis. 1992. Multiple retinoid-response receptors in a single cell: Families of retinoid " $\mathrm{X}$ " receptors and retinoic acid receptors in the Xenopus egg. Proc. Natl. Acad. Sci. 89: 2321-2325.

Bolce, M.E., A. Hemmati-Brivanlou, P.D. Kushner, and R.M. Harland. 1992. Ventral ectoderm of Xenopus forms neural tissue, including hindbrain, in response to activin. Development 115: 673-680.

Busa, W.B. and R.L. Gimlich. 1988. Lithium-induced teratogenesis in frog embryos prevented by a polyphosphoinositide cycle intermediate or a diacylglycerol analog. Dev. Biol. 132: 315-324.

Cho, K.W.Y. and E.M. De Robertis. 1990. Differential activation of Xenopus homeo box genes by mesoderm-inducing growth factors and retinoic acid. Genes \& Dev. 4: 1910-1916.

Cho, K.W.Y., B. Blumberg, H. Steinbeisser, and E.M. De Robertis. 1991. Molecular nature of Spemann's Organizer: The role of the Xenopus homeobox gene goosecoid. Cell 67: 1111-1120.

Christian, J.L., J.A. McMahon, A.P. McMahon, and R.T. Moon. 1991. Xwnt-8, a Xenopus Wnt-1/int-1-related gene responsive to mesoderm-inducing growth factors, may play a role in ventral mesodermal patterning during embryogenesis. Development 111: 1045-1055.

Christian, J.L., D.J. Olson, and R.T. Moon. 1992. Xwnt-8 modifies the character of mesoderm induced by bFGF in isolated Xenopus ectoderm. EMBO /. 11: 33-41.

Cooke, J. 1985. The system specifying body position in the early development of Xenopus, and its response to early perturbations. J. Embryol. Exp. Morphol. (suppl.) 89: 69-87.

Cooke, J. and J.C. Smith. 1989. Gastrulation and larval pattern in Xenopus after blastocoelic injection of Xenopus-derived inducing factor: Experiments testing models for the normal organization of mesoderm. Dev. Biol. 131: 383-400.

Cooke, J. and J.A. Webber. 1985. Dynamics of the control of body pattern in the development of Xenopus laevis. I. Timing and pattern in the development of dorso-anterior and posterior blastomere pairs isolated at the 4-cell stage. J. Embryol. Exp. Morphol. 88: 85-112.

Cooke, J., K. Symes, and E.J. Smith. 1989. Potentiation by the lithium ion of morphogenetic responses to a Xenopus inducing factor. Development 105: 549-558.

Cunliffe, V. and J.C. Smith. 1992. Ectopic mesoderm formation in Xenopus embryos caused by widespread expression of Brachyury homologue. Nature 358: 427-430.

Dale, L. and J.M.W. Slack. 1987a. Fate map for the 32-cell stage of Xenopus laevis. Development 99: 527-551.

- 1987b. Regional specification within the mesoderm of early embryos of Xenopus laevis. Development 100: 279295.

Dale, L., G. Howes, B.M.J. Price, and J.C. Smith. 1992. Bone 
morphogenetic protein 4: a ventralizing factor in early $X e$ nopus development. Development 115: 573-585.

Dirksen, M.L. and M. Jamrich. 1992. A novel, activin-inducible, blastopore lip-specific gene of Xenopus laevis contains a fork head DNA-binding domain. Genes \& Dev. 6: 599-608.

Durston, A.J., J.P.M. Timmermans, W.J. Hage, H.F.J. Hendriks, N.J. de Vries, M. Heideveld, and P.D. Nieuwkoop. 1989. Retinoic acid causes an anteroposterior transformation in the developing central nervous system. Nature 340: 140-144.

Elinson, R.P. and P. Pasceri. 1989. Two UV-sensitive targets in dorsoanterior specification of frog embryos. Development 106: $511-518$.

Frank, D. and R.M. Harland. 1991. Transient expression of $\mathrm{XMyoD}$ in non-somitic mesoderm of Xenopus gastrulae. Development 113: 1387-1393.

Gallagher, B.C., A.M. Hainski, and S.A. Moody. 1991. Autonomous differentiation of dorsal axial structures from an animal cap cleavage stage blastomere in Xenopus. Development 112: 1103-1114.

Gerhart, J., M. Danilchik, T. Doniach, S. Roberts, B. Rowning, and R. Stewart. 1989. Cortical rotation of the Xenopus egg: Consequences for the anteroposterior pattern of embryonic dorsal development. Development (Suppl.) 107: 37-51.

Gimlich, R.L. 1986. Acquisition of developmental autonomy in the equatorial region of the Xenopus embryo. Dev. Biol. 115: $340-352$.

Gimlich, R.L. and J.C. Gerhart. 1984. Early cellular interactions promote embryonic axis formation in Xenopus laevis. Dev. Biol. 104: 117-130.

Green, J.B.A. and J.C. Smith. 1990. Graded changes in dose of a Xenopus activin A homologue elicit stepwise transitions in embryonic cell fate. Nature 347: 391-394.

Green, J.B.A., G. Howes, K. Symes, J. Cooke, and J.C. Smith. 1990. The biological effects of XTC-MIF: Quantitative comparison with Xenopus bFGF. Development 108: 173-183.

Green, J.B.A., H.V. New and J.C. Smith. 1992. Responses of embryonic Xenopus cells to activin and FGF are separeted by multiple dose thresholds and correspond to distinct axes of the mesoderm. Cell (in press).

Harvey, R.P. 1990. The Xenopus MyoD gene: An unlocalised maternal mRNA predates lineage-restricted expression in the early embryo. Development 108: 669-680.

- 1992. MyoD protein expression in Xenopus embryos closely follows a mesoderm induction-dependent amplification of $M y o D$ transcription and is synchronous across the future somite axis. Mech. Dev. 37: 141-149.

Hemmati-Brivanlou, A. and D.A. Melton. 1992. A truncated activin receptor inhibits mesoderm induction and formation of axial structures in Xenopus embryos. Nature 359: 609614.

Hopwood, N.D. and J.B. Gurdon. 1990. Activation of muscle genes without myogenesis by ectopic expression of MyoD in frog embryo cells. Nature 347: 197-200.

Hopwood, N.D., A. Pluck, and J.B. Gurdon. 1989. MyoD expression in the forming somites is an early response to mesoderm induction in Xenopus embryos. EMBO I. 8: 34093417.

Jones, C.M., K.M. Lyons, P.M. Lapan, C.V.E. Wright, and B.L.M. Hogan. 1992. DVR-4 (bone morphogenetic protein-4) as a posterior-ventralizing factor in Xenopus mesoderm induction. Development 115: 639-647.

Kageura, H. 1990. Spatial distribution of the capacity to initiate a secondary embryo in the 32-cell embryo of Xenopus laevis. Dev. Biol. 142: 432-438.

Kao, K.R. and R.P. Elinson. 1988. The entire mesodermal mantle behaves as Spemann's Organizer in dorsoanterior en- hanced Xenopus laevis embryos. Dev. Biol. 127: 64-77.

. 1989. Dorsalization of mesoderm induction by lithium. Dev. Biol. 132: 81-90.

Keller, R.E. 1976. Vital dye mapping of the gastrula and neurula of Xenopus laevis II Prospective areas and morphogenetic movements of the deep layer. Dev. Biol. 51:118-137.

Kimelman, D. and M. Kirschner. 1987. Synergistic indiction of mesoderm by FGF and TGF $\beta$ and the identification of an mRNA coding for FGF in the early Xenopus embryo. Cell 51: 369-377.

Kimelman, D. and A. Maas. 1992. Induction of dorsal and ventral mesoderm by ectopically expressed Xenopus basic fibroblast growth factor. Development 114: 261-269.

Kimelman, D., J.L. Christian, and R.T. Moon. 1992. Synergistic principles of development: Overlapping patterning systems in Ye 1opus mesoderm induction. Development 116: 1-9.

Kimelman, D., J.A. Abraham, T. Haaparanta, T.M. Palisi, and M.W. Kirschner. 1988. The presence of fibroblast growth factor in the frog egg: Its role as a nature mesoderm inducer. Science 242: 1053-1056.

Kirschner, M., J. Newport, and J. Gerhart. 1985. The timing of early developmental events in Xenopus. Trends Genet. 1: $41-47$.

Koster, M., S. Plessow, J. H. Clement, A. Lorenz, H. Tiedemann, and W. Knochel. 1991. Bone morphogenetic protein 4 (BMP4 ), a member of the TGF- $\beta$ family, in early embryos of Xenopus laevis: Analysis of mesoderm inducing activity. Mech. Dev. 33: 191-200.

Mathews, L.S., W.W. Vale, and C.R. Kintner. 1992. Cloning of a second type of activin receptor and functional characterization in Xenopus embryos. Science 255: 1702-1705.

Mosquera, L., C. Forristall, Y. Zhou, and M. L. King. 1993. A mRNA localized to the vegetal cortex of Xenopus oocytes encodes a protein with a nanos-like zinc finger domain. $D e$ velopment (in press).

Musci, T.J., E. Amaya, and M.W. Kirschner. 1990. Regulation of the fibroblast growth factor recptor in early Xenopus embryos. Proc. Natl. Acad. Sci. 87: 8365-8369.

Nakamura, O., H. Takasaki, and T. Mizohata. 1970. Differentiation during cleavage in Xenopus laevis (acquisition of selfdifferentiation capacity of the dorsal marginal zone). Proc. Ipn. Acad. 46: 694-699.

Nieuwkoop, P.D. 1973. The "organization center" of the amphibian embryo; its origin spatial organization and morphogenic action. Adv. Morphog. 10: 2-39.

Olson, D.J., J.L. Christian, and R.T. Moon. 1991. Effect of WNT-1 and related proteins on gap junctional communication in Xenopus embryos. Science 252: 1173-1176.

Otte, A.P. and R.T. Moon. 1992a. Protein kinase C isozymes have distinct roles in neural induction and competence in Xenopus. Cell 68: 1021-1029.

- 1992b. Ectopic induction of dorsal mesoderm by overexpression os Xwnt-8 elevates the neural competence of $X e$ nopus ectoderm. Dev. Biol. 152: 184-187.

Otte, A.P., I.M. Kramer, and A.J. Durston. 1991. Protein Kinase $\mathrm{C}$ and regulation of the local competence of Xenopus ectoderm. Science 251: 570-573.

Pondel, M.D. and M.L. King. 1988. Localized maternal mRNA related to transforming growth factor $\beta$ mRNA is concentrated in a cytokeratin-enriched fraction from Xenopus oocytes. Proc. Natl. Acad. Sci. 85: 7612-7616.

Rosa, F.M. 1989. Mix.1, an Homeobox mRNA inducible by mesoderm inducers, is expressed mostly in the presumptive endodermal cells of Xenopus embryos. Cell 57: 965-974.

Ruiz i Altaba, A. and T. Jessell. 1991. Retinoic acid modifies mesodermal patterning in early Xenopus embryos. Genes \& 
Dev. 5: 175-187.

Ruiz i Altaba, A. and D. A. Melton. 1989. Interaction between peptide growth factors and homoeobox genes in the establishment of antero-posterior polarity in frog embryos. $\mathrm{Na}$ ture 341: 33-38.

. 1989. Involvement of the Xenopus homeobox gene Xhox 3 in pattern formation along the anterior-posterior axis. Cell 57: 317-326.

Rupp, R.A.W. and H. Weintraub. 1991. Ubiquitous MyoD transcription at the midblastula transition precedes inductiondependent MyoD expression in presumptive mesoderm of Xenopus laevis. Cell 65: 927-938.

Sargent, M.G. and M.F. Bennett. 1990. Identification in Xenopus of a structural homologue of the Drosophila gene Snail. Development 109: 967-973.

Savage, R. and C.R. Phillips. 1989. Signals from the dorsal blastopore lip region during gastrulation bias the ectoderm toward a nonepidermal pathway of differentiation in Xenopus laevis. Dev. Biol. 133: 157-168.

Sharpe, C.R., A. Fritz, E.M. De Robertis, and J.B. Gurdon. 1987. A homeobox-containing marker of posterior neural differentiation shows the importance of predetermination of neural induction. Cell 50: 749-758.

Shiurba, R.A., N. Jing, T. Sakakura, and S.F. Godsave. 1991. Nuclear translocation of fibroblast growth factor during $\mathrm{Xe}$ nopus mesoderm induction. Development 113: 487-493.

Sive, H.L. and P.F. Cheng. 1991. Retinoic acid perturbs the expression of Xhox.lab genes and alters mesodermal determination in Xenopus laevis. Genes \& Dev. 5: 1321-1332.

Sive, H.L., B.W. Draper, R.M. Harland, and H. Weintraub. 1990. Identification of a retinoic acid-sensitive period during primary axis formation in Xenopus laevis. Genes \& Dev. 4: 932-942.

Slack, J.M.W. and H.V. Isaacs. 1989. Presence of basic fibroblast growth factor in the early Xenopus embryo. Development 105: $147-153$.

Slack, J.M.W. and D. Tannahill. 1992. Mechanism of anteroposterior axis specification in vertebrates (lessons from the amphibians). Development 114: 285-302.

Slack, J.M.W., H.V. Isaacs, and B.G. Darlington. 1988. Inductive effects of fibroblast growth factor and lithium ion on Xenopus blastula ectoderm. Development 103: 581-590.

Smith, J.C. 1989. Mesoderm induction and mesoderm-inducing factors in early amphibian development. Development 105: 665-677.

Smith, J.C. and J.M.W. Slack. 1983. Dorsalization and neural induction: Properties of the organizer in Xenopus laevis. /. Embryol. Exp. Morphol. 78: 299-317.

Smith, J.C., B.M.J. Price, J.B.A. Green, D. Weigel, and B.G. Herrmann. 1991. Expression of a Xenopus homolog of Brachyury $(T)$ is an immediate-early response to mesoderm induction. Cell 67: 79-87.

Smith, W.C. and R.M. Harland. 1991. Injected Xwnt-8 RNA acts early in Xenopus embryos to promote formation of a vegetal dorsalizing center. Cell 67: 753-765.

- 1992. Expression cloning of noggin, a new dorsalizing factor localized in the Spemann organizer in Xenopus embryos. Cell 70: 829-840.

Sokol, S. and D.A. Melton. 1991. Pre-existent pattern in Xenopus animal pole cells revealed by induction with activin. Nature 351: 409-411.

Sokol, S., J.L. Christian, R.T. Moon, and D.A. Melton. 1991. Injected Wnt RNA induces a complete body axis in Xenopus embryos. Cell 67: 741-752.

. 1992. Interaction of Wnt and activin in dorsal mesoderm induction in Xenopus. Dev. Biol. 154: 348-355.
Spemann, H. 1938. Embryonic development and induction. Yale University Press, New Haven, CT.

Stewart, R.M. and J.C. Gerhart. 1990. The anterior extent of dorsal development of the Xenopus embryonic axis depends on the quantity of organizer in the late blastula. Development 109: 363-372.

Taira, M., M. Jamrich, P.J. Good, and I.B. Dawid. 1992. The LIM domain-contianing homeo box gene Xlim-1 is expressed specifically in the organizer region of Xenopus gastrula embryos. Genes \& Dev. 6: 356-366.

Tannahill, D., H.V. Isaacs, M.J. Close, G. Peters, and J.M.W. Slack. 1992. Developmental expression of the Xenopus int-2 (FGF-3) gene: Activation by mesodermal and neural induction. Development 115: 695-702.

Thompson, J. and J.M.W. Slack. 1992. Overexpression of fibroblast growth factors in Xenopus embryos. Mech. Dev. 38: 175-182.

Thomsen, G., T. Woolf, M. Whitman, S. Sokol, J. Vaughan, W. Vale, and D.A. Melton. 1990. Activins are expressed early in Xenopus embryogenesis and can induce axial mesoderm and anterior structures. Cell 63: 485-493.

Weeks, D.L. and D.A. Melton. 1987. A maternal mRNA localized to the vegetal hemisphere in Xenopus eggs codes for a growth facted related to TGF- $\beta$. Cell 51: 861-867.

Whitman, M. and D.A. Melton. 1992. Involvement of $\mathrm{p} 21^{\text {ras }}$ in Xenopus mesoderm induction. Nature 357: 252-254.

Yamada, T. 1950. Dorsalization of the ventral marginal zone of the Trituris gastrula. I. Ammonia-treatement of the mediolateral marginal zone. Bull. Mar. Biol. Lab. Woods Hole 98: $98-121$. 


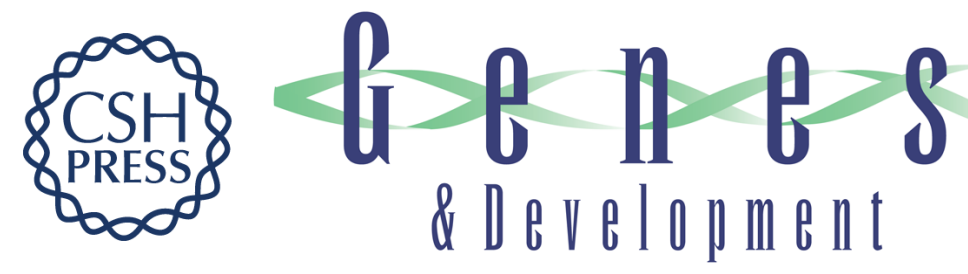

\section{The frog prince-ss: a molecular formula for dorsoventral patterning in Xenopus.}

H L Sive

Genes Dev. 1993, 7:

Access the most recent version at doi:10.1101/gad.7.1.1

References This article cites 84 articles, 38 of which can be accessed free at:

http://genesdev.cshlp.org/content/7/1/1.full.html\#ref-list-1

License

Email Alerting

Receive free email alerts when new articles cite this article - sign up in the box at the

Service top right corner of the article or click here.

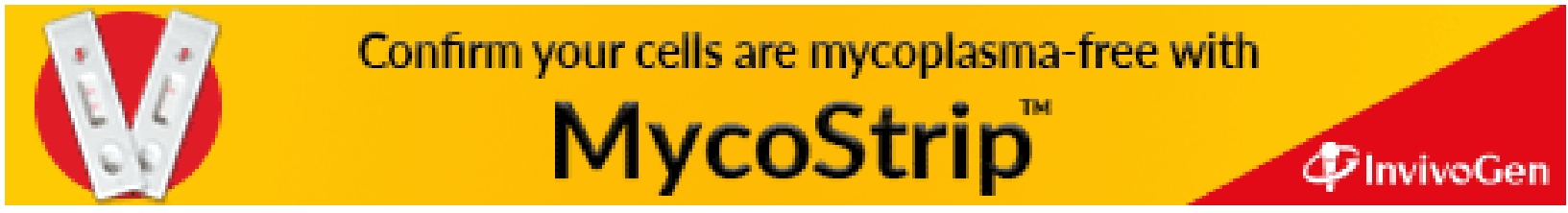

